\title{
Discovery and antitumor activities of constituents from Cyrtomium fortumei (J.) Smith rhizomes
}

\author{
Shengjie Yang ${ }^{1,2}$, Mingchuan Liu ${ }^{1,2}$, Na Liang $^{1,2}$, Qi Zhao ${ }^{1,2}$, Yuping Zhang ${ }^{1,2}$, Wei Xue $e^{1,2}$ and Song Yang ${ }^{1,2^{*}}$
}

\begin{abstract}
Background: Cyrtomium fortumei (J.) Smith is an important Chinese herbal medicine because of its biological functions. However, systematic and comprehensive studies on the phytochemicals from Cyrtomium fortumei (J.) Smith and their bioactivity are limited.
\end{abstract}

Results: Using the bioassay-guided technique, the ethyl acetate and $n-\mathrm{BuOH}$ extracts of the rhizomes of Cyrtomium fortumei (J.) Smith were shown to exhibit good antitumor activities, consequently leading to the isolation of 23 compounds. All compounds were isolated from the plant for the first time. The inhibitory activities of these compounds were investigated on tumor cells MGC-803, PC3, and A375 in vitro by MTT (thiazolyl blue tetrazolium bromide) assay, and the results showed that pimpinellin (3) had potent cytotoxic activities against the three cell lines, with the $I_{50}$ values of $14.4 \pm 0.3 \mu \mathrm{M}, 20.4 \pm 0.5 \mu \mathrm{M}$, and $29.2 \pm 0.6 \mu \mathrm{M}$, respectively. The mechanism of the antitumor action indicated that pimpinellin inhibited the growth of MGC-803 cells via the induction of tumor cell apoptosis, with apoptosis ratio of $27.44 \%$ after $72 \mathrm{~h}$ of treatment at $20 \mu \mathrm{M}$.

Conclusions: This study suggests that most of the compounds from the roots of Cyrtomium fortumei (J.) Smith could inhibit the growth of human carcinoma cells. Moreover, pimpinellin inhibited the growth of tumor cells via the induction of tumor cell apoptosis.

\section{Background}

Cyrtomium fortumei (J.) Smith belongs to the Dryopteridaceae family which comprises approximately 14 genera and 1700 species throughout the world, and is widely spread in tropical and subtropical regions. The Chinese Pharmacopoeia (2005 edition) listed Cyrtomium fortumei (J.) Smith as an official drug, which showed that the plant could be used as anticancer herbs [1]. In the past, people used the rhizomes and extracts from the plant as vermifuges [2]. The plant can be used to cure many diseases, such as influenza, acute and chronic pharyngitis, cancer, and migraine [3]. In addition, the herb was used as antiviral agents to cure severe acute respiratory syndrome, a life-threatening viral respiratory illness believed to be caused by a coronavirus [4]. Furthermore, phoroglucinols and flavonoids are known to display a wide

\footnotetext{
* Correspondence: jhzx.msm@gmail.com

'State Key Laboratory Breeding Base of Green Pesticide and Agricultural Bioengineering, Key Laboratory of Green Pesticide and Agricultural

Bioengineering, Ministry of Education, Guizhou University, Guiyang 550025, P.R. China

${ }^{2} \mathrm{Ctr}$ for R\&D of Fine Chemicals, Guizhou University, Huaxi St, Guiyang
} 550025, China array of pharmacological and biochemical actions, and have been isolated from many species of the Dryopteridaceae family [5]. However, so far the constituents with anticancer activity of the plant remain unclear. Thus it is necessary to identify the potent antitumor compounds from this plant.

We have recently investigated the chemical constituents of Cyrtomium fortumei (J.) Smith systematically, and tested the antitumor activities of the extracts and compounds. The current study was conducted to validate the medicinal use of Cyrtomium fortumei (J.) Smith. 23 compounds were isolated from the ethyl acetate and $n-\mathrm{BuOH}$ extracts, and their structures were elucidated to be protocate chaldehyde (1), woodwardinsauremethylester (2), pimpinellin (3), trans-2-coumaric acid (4), physcion (5), ursolic acid (6), sitost-4-en-3-one (7), betulin (8), $3^{\prime}, 4^{\prime}, 5$-Trihydroxy-3,7-dimethoxyflavone (9), woodwardinic acid $(\mathbf{1 0})$, sitosterol-3-O- $\beta$-D-glucopyranoside (11), sutchuenoside A (12), $\beta$-sitosterol (13), kaempferol-3,7-O- $\alpha$-L-dirhamnoside (14), (-)-epicatchin (15), (+)-catechin hydrate (16), kaempferol (17), asiatic

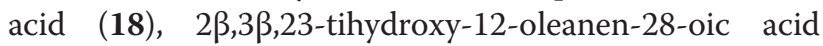

(C) Chemistry Central

(c) 2013 Yang et al.; licensee Chemistry Central Ltd. This is an Open Access article distributed under the terms of the Creative Commons Attribution License (http://creativecommons.org/licenses/by/2.0), which permits unrestricted use, distribution, and reproduction in any medium, provided the original work is properly cited. 
(19), crassirhizomoside A (20), kaempferol-3-O-(3-Oacetyl- $\alpha$-L-rhamnopyranoside) (21), $2 \alpha, 3 \alpha, 24$-trihydroxyurs-12-en-28-oic acid (22), and kaempferol-3-O- $\alpha$-Lrhamnopyranoside-7-O- $\alpha$-L-rhamopyranoside (23). All compounds were isolated from Cyrtomium fortumei (J.) Smith for the first time. The inhibitory activities of these compounds were investigated on tumor cells MGC-803, PC3, and A375 in vitro by MTT (thiazolyl blue tetrazolium bromide) assay, and the results indicated that some of the compounds showed good antitumor activities. It was found that pimpinellin (PPI) had most potent cytotoxic activities against the three cell lines, with the $\mathrm{IC}_{50}$ values of $14.4 \pm 0.3 \mu \mathrm{M}, 20.4 \pm 0.5 \mu \mathrm{M}$, and $29.2 \pm$ $0.6 \mu \mathrm{M}$, respectively. However, no report was found on apoptosis inducing activity of PPI. Subsequent staining and flow cytometry (FCM) analysis indicated that PPI could apoptosis in MGC-803 cells, with the highest apoptosis ratio of $27.44 \%$ at $72 \mathrm{~h}$ after treatment at $20 \mu \mathrm{M}$.

\section{Results and discussion Isolation and identification}

Dried rhizomes of Cyrtomium fortumei (J.) Smith $(10 \mathrm{~kg})$ were cut into pieces and extracted with $80 \%$ $\mathrm{EtOH}(3 \times 40 \mathrm{~L})$ under reflux, $6 \mathrm{~h}$ for the first time, $3 \mathrm{~h}$ for the second time, and $1 \mathrm{~h}$ for the last time. The combined EtOH extracts were evaporated to dryness to yield a dried EtOH extract (424 g). The extract was suspended in water and then extracted with petroleum ether (10 $\mathrm{L} \times 3$ times), ethyl acetate (10 $\mathrm{L} \times 3$ times), and $n$ $\mathrm{BuOH}(10 \mathrm{~L} \times 3$ times), respectively. Different extracts solvent were then concentrated using evaporator under vacuum at $50^{\circ} \mathrm{C}$ to afford the petroleum ether extract $(46 \mathrm{~g})$, ethyl acetate extract $(95 \mathrm{~g})$, and $n-\mathrm{BuOH}$ extract $(110 \mathrm{~g})$. MTT assay was used to evaluate their antitumor activities. The results suggested that the antitumor agents were mainly contained in ethyl acetate and $n$ $\mathrm{BuOH}$ extracts. Further experiments were performed on ethyl acetate and $n-\mathrm{BuOH}$ extracts to separate antitumor compounds. The ethyl acetate and $n-\mathrm{BuOH}$ extracts were subjected to column chromatography $(\mathrm{CC})$ to yield 16 fractions. An activity-directed isolation process was used to get compounds, and 23 compounds were obtained from these fractions.

The isolated compounds were identified via spectroscopic analyses, including ${ }^{1} \mathrm{H}$ - and ${ }^{13} \mathrm{C}$-NMR spectroscopy. The results of the analyses were compared with the NMR and IR data reported in literatures to identify the chemical structures. All compounds were isolated from Cyrtomium fortumei (J.) Smith for the first time.

\section{Biological evaluation}

The potential effect of the extracts from Cyrtomium fortumei (J.) Smith was investigated on the viability of
MGC-803, PC3, A375, and NIH3T3 cells using MTT assay at the concentration of $20 \mu \mathrm{M}$, with ADM (Adriamycin) being used as the positive control and DMSO being used as the negative control. The inhibitory percentage of cells was treated with $20 \mu \mathrm{M}$ or $50 \mu \mathrm{g} / \mathrm{mL}$ of each compound or extract for $72 \mathrm{~h}$ (Table 1). The results showed that the ethyl acetate and $n-\mathrm{BuOH}$ extracts had great antitumor activity, and PPI had good activities against the three human cancer cell lines tested than other compounds. The inhibitory ratios of PPI at $72 \mathrm{~h}$ after treatment were $67.1 \%$ on MGC-803 cells, $57.2 \%$ on PC3 cells, $45.8 \%$ on A375 cells, and $24.8 \%$ on NIH3T3 cells. It could be seen that PPI had good antitumor activities and low cytotoxic effect on normal cell line NIH3T3. Further experiments found that proliferation of these three carcinoma cells were significantly inhibited by PPI in a concentration-dependent manner, as shown in Figure 1. The $\mathrm{IC}_{50}$ values of PPI against MGC803, PC3, and A375 cells were determined to be $14.4 \pm$ $0.3 \mu \mathrm{M}, 20.4 \pm 0.5 \mu \mathrm{M}$, and $29.2 \pm 0.6 \mu \mathrm{M}$, respectively, which were lower than that on NIH3T3 cells $\left(\mathrm{IC}_{50}>\right.$ $100 \mu \mathrm{M})$.

To determine whether the growth inhibitory activity of PPI was related to the induction of apoptosis, the morphological character changes of MGC-803 cells were investigated using the AO/EB staining, Hoechst 33258 staining, and TUNEL assay.

The cell morphologic changes after PPI treatment were assessed by fluorescence microscopy after AO/EB staining [6]. $\mathrm{AO}$ is a vital dye that could penetrate the normal cell membrane [7], whereas EB will stain only those cells that have lost their membrane integrity [8]. The stained cells revealed four different types under a fluorescence microscope: the chromatin of living cells was green with normal structure; the chromatin of nonapoptotic dead cells was red with normal structure; yellow coloration of early apoptotic cells with morphous in the form of pycnosis; and orange coloration of late apoptotic cells with morphous in the form of pycnosis [9-13]. With hydroxycamptothecine (HCPT) as positive control, the cytotoxicity of PPI at a concentration of $20 \mu \mathrm{M}$ against MGC-803 cells for $24 \mathrm{~h}$ was detected via AO/EB staining.

As can be seen in Figure 2A, green live MGC-803 cells with normal morphology were seen in the negative control group. Green yellow or orange dots were detected in the HCPT after $24 \mathrm{~h}$. After cells were treated with PPI for $24 \mathrm{~h}$, the nuclei stained as yellow green or orange, and the morphology showed pycnosis, membrane blebbing and cell budding. These phenomena indicate PPI could induce apoptosis without any significant cytotoxicity.

Live cells with uniformly light blue nuclei were treated with Hoechst 33258 [14-17] and observed under a 
Table 1 Growth inhibition effect of various constituents of Cyrtomium fortumei (J.) Smith on different cell lines

\begin{tabular}{|c|c|c|c|c|}
\hline \multirow[t]{2}{*}{ Test extracts and compounds } & \multicolumn{4}{|c|}{ Inhibitory Rate for Different Cell Lines $\left(\%\right.$, mean \pm SD) ${ }^{a}$} \\
\hline & MGC-803 ${ }^{b}$ & PC3 ${ }^{\mathrm{C}}$ & $A 375^{d}$ & NIH3T3 ${ }^{e}$ \\
\hline Petroleum ether extract ${ }^{f}$ & $56.7 \pm 3.7$ & $68.0 \pm 1.9$ & $60.5 \pm 3.2$ & $7.1 \pm 3.8$ \\
\hline Ethyl acetate extract ${ }^{f}$ & $80.3 \pm 2.8$ & $89.6 \pm 1.5$ & $88.7 \pm 3.3$ & $45.6 \pm 4.0$ \\
\hline$n-\mathrm{BuOH}$ extract ${ }^{f}$ & $87.2 \pm 3.9$ & $80.2 \pm 2.4$ & $85.2 \pm 3.7$ & $53.5 \pm 8.6$ \\
\hline ADM & $93.2 \pm 1.6$ & $95.1 \pm 2.6$ & $95.2 \pm 2.4$ & $98.5 \pm 1.7$ \\
\hline Protocate chaldehyde (1) & $17.8 \pm 3.1$ & $30.5 \pm 2.4$ & $25.7 \pm 3.1$ & $12.1 \pm 3.7$ \\
\hline Woodwardinsaure methylester (2) & $47.9 \pm 9.3$ & $33.2 \pm 2.8$ & $41.4 \pm 5.6$ & $15.2 \pm 2.6$ \\
\hline PPI (3) & $67.1 \pm 5.3$ & $57.2 \pm 4.2$ & $45.8 \pm 7.8$ & $24.8 \pm 3.4$ \\
\hline Physcion (5) & $28.9 \pm 2.2$ & $20.7 \pm 1.2$ & $15.7 \pm 5.9$ & $4.5 \pm 2.6$ \\
\hline Ursolic acid (6) & $52.6 \pm 2.4$ & $55.8 \pm 3.1$ & $43.2 \pm 1.3$ & $23.4 \pm 3.3$ \\
\hline Sitost-4-en-3-one (7) & $35.8 \pm 2.6$ & $15.3 \pm 5.8$ & $26.4 \pm 5.1$ & $5.2 \pm 2.7$ \\
\hline Betulin (8) & $45.1 \pm 3.1$ & $18.4 \pm 3.1$ & $33.9 \pm 5.6$ & $29.8 \pm 2.5$ \\
\hline 31,41,5-Trihydroxy-3,7-dimethoxyflavone (9) & $25.6 \pm 3.9$ & $20.3 \pm 2.5$ & $11.2 \pm 6.2$ & $10.0 \pm 2.9$ \\
\hline Woodwardinic acid (10) & $25.1 \pm 5.3$ & $25.2 \pm 1.3$ & $38.6 \pm 4.0$ & $6.9 \pm 2.0$ \\
\hline Sutchuenoside A (12) & $19.9 \pm 9.8$ & $12.3 \pm 4.4$ & $34.8 \pm 5.3$ & $8.8 \pm 4.2$ \\
\hline Kaempferol-3, 7-O-a-L-dirhamnoside (14) & $21.5 \pm 7.0$ & $17.8 \pm 5.5$ & $36.7 \pm 3.9$ & $23.1 \pm 3.2$ \\
\hline (-)-Epicatchin (15) & $45.5 \pm 4.1$ & $50.6 \pm 1.6$ & $45.3 \pm 3.2$ & $22.5 \pm 3.8$ \\
\hline (+)-Catechin hydrate (16) & $52.1 \pm 5.7$ & $49.6 \pm 2.3$ & $46.8 \pm 1.1$ & $28.9 \pm 4.3$ \\
\hline Kampferol (17) & $54.5 \pm 2.4$ & $44.3 \pm 2.5$ & $47.3 \pm 1.9$ & $12.2 \pm 3.4$ \\
\hline Crassirhizomoside A (20) & $11.4 \pm 2.3$ & $20.8 \pm 6.0$ & $34.9 \pm 2.7$ & $12.5 \pm 5.2$ \\
\hline Kaempferol-3-O-(3-O-acetyl-a-L-rhamnopyranoside) (21) & $22.6 \pm 8.0$ & $15.6 \pm 6.1$ & $17.8 \pm 3.3$ & $9.9 \pm 6.1$ \\
\hline
\end{tabular}

Note: ${ }^{a}$ Inhibitory percentage of cells treated with $20 \mu \mathrm{M}$ of each compound for $72 \mathrm{~h}$ and SD = standard deviation; ${ }^{\mathrm{b}}$ Stomach cancer; ${ }^{\mathrm{c}}$ Prostate cancer; ${ }^{\mathrm{d}}$ Malignant melanoma; ${ }^{e}$ Mouse fibroblasts; ${ }^{f}$ Inhibitory percentage of cells treated with $200 \mu \mathrm{g} / \mathrm{mL}$ of each extract for $72 \mathrm{~h}$.

fluorescence microscope. However, apoptotic cells had bright blue nuclei because of karyopyknosis and chromatin condensation; the nuclei of dead cells could not be stained [18-22]. With hydroxycamptothecine (HCPT) as

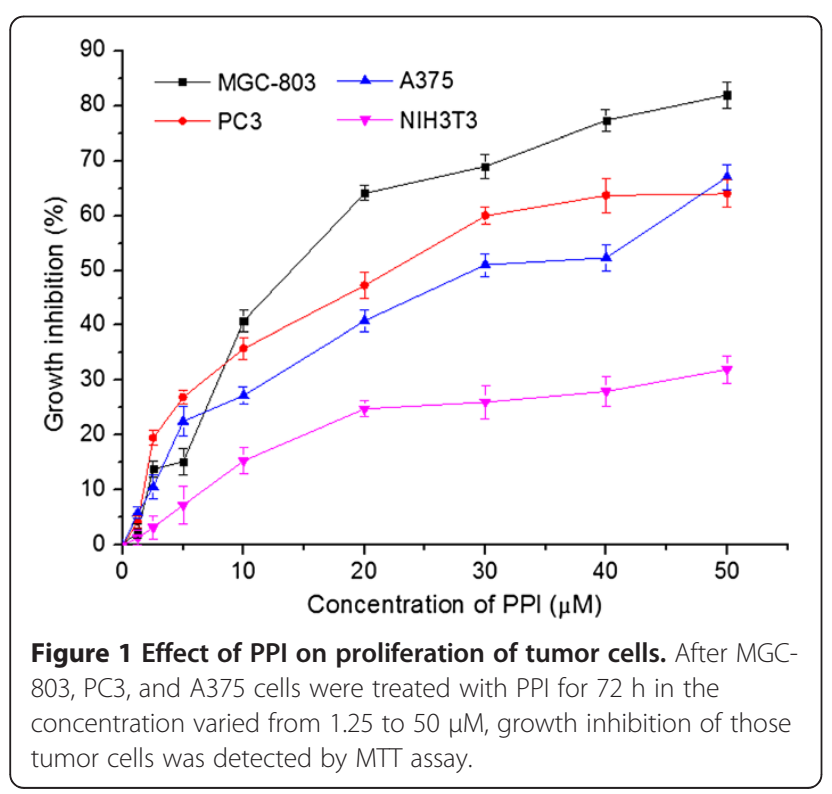

positive control, MGC-803 cells treated with PPI at $20 \mu \mathrm{M}$ for $24 \mathrm{~h}$ were stained with Hoechst 33258 .

As can be seen in Figure 2B, the cells of the negative group (DMSO) were normal blue. However, the cells of HCPT treatment appeared to be compact and condensed. After treatment with PPI for $24 \mathrm{~h}$, most of cell nuclei appeared to be highly condensed and crescentshaped, indicating that PPI induced apoptosis against

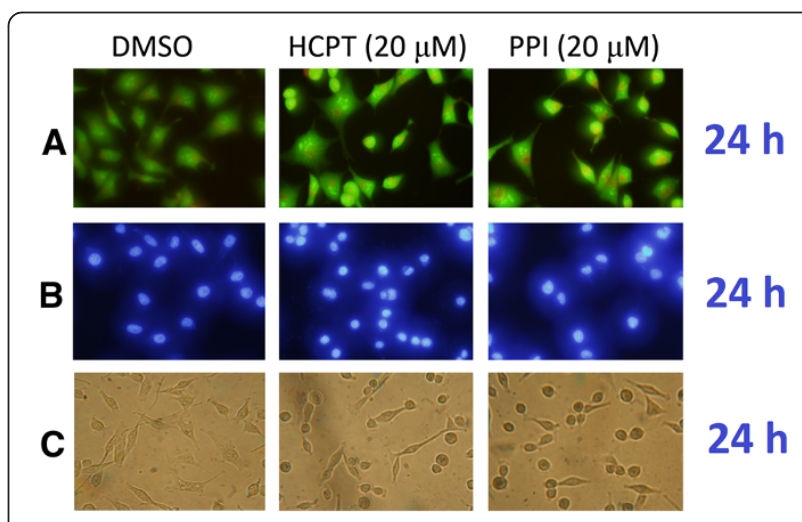

Figure 2 Apoptosis induction studies of PPI. (A) AO\EB staining. (B) Hoechst 33258 staining. (C) TUNEL assay. 
MGC-803 cell lines. These results were consistent with $\mathrm{AO} / \mathrm{EB}$ double staining.

In addition, TUNEL, one of the popular methods, identified apoptotic cells in situ via the detection of DNA fragmentation $[23,24]$. Under a biological microscope, the cells were observed that where brown precipitate was the result of positive apoptosis [25-27]. MGC-803 cells were treated PPI and HCPT $20 \mu \mathrm{M}$ at with for $24 \mathrm{~h}$.

As can be seen in Figure $2 \mathrm{C}$, the cells of the negative group (DMSO) did not appear as brown precipitates, whereas both PPI and HCPT appeared as brown precipitates. Therefore, it can be further concluded that PPI induced apoptosis against MGC-803 cells. The results were identical with the previous experiment.

The apoptosis ratios induced by PPI in tumor cells was quantitatively assessed by FCM [28]. In early apoptotic cells, phosphatidylserine (PS) which distributed inside the lipid bilayer in the normal cells was transferred from the inside of the cell membrane to the outside. Annexin $\mathrm{V}$, a $\mathrm{Ca}^{2+}$ dependent phospholipid-binding protein with a high affinity for PS, was used to detect early apoptotic cells. PI (Propidine Iodide) was a red fluorescent dye and stained cells that had lost membrane integrity. So, the different periods of apoptotic cells could be distinguished when Annexin V matched with PI: necrotic cells (the upper left quadrant, Annexin ${ }^{-} / \mathrm{PI}^{+}$), late apoptotic cells (the upper right quadrant, Annexin ${ }^{+} / \mathrm{PI}^{+}$), intact cells (the lower left quadrant, Annexin ${ }^{-} / \mathrm{PI}^{-}$) and early apoptotic cells (the lower right quadrant, Annexin $\left.{ }^{+} / \mathrm{PI}^{-}\right)[29,30]$. As shown in Figure 3, with HCPT as positive control, PPI could induce apoptosis of MGC-803 cells, with the highest apoptosis ratio of $27.44 \%$ at $72 \mathrm{~h}$ after treatment at $20 \mu \mathrm{M}$. Furthermore, as shown in Figure 4 the apoptosis of MGC-803 which treated with PPI increased gradually in a time-dependent manner.

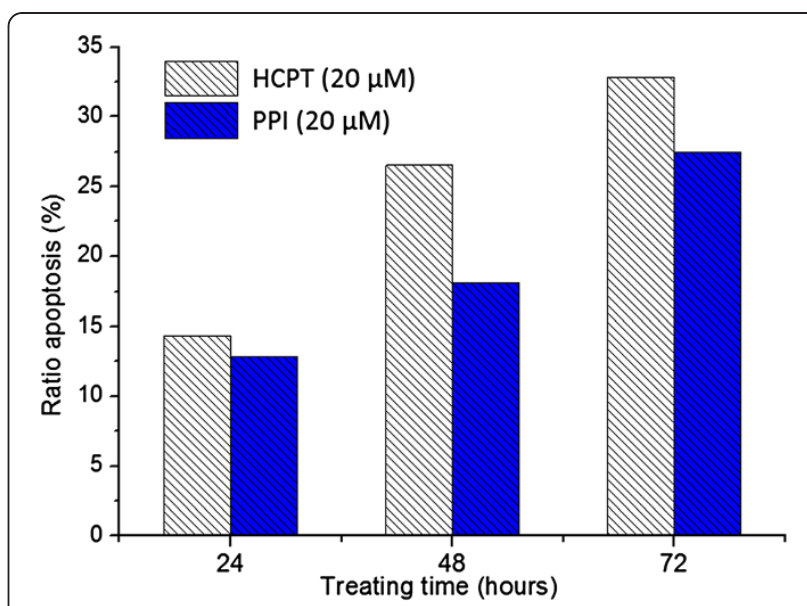

Figure 4 Effects of concentration of PPI on apoptosis. These cells were treated with HCPT and PPI for 24, 48, and $72 \mathrm{~h}$.

\section{Conclusions}

In this study, an activity-directed fractionation and purification process were used to isolate antitumor compounds from the rhizomes of Cyrtomium fortumei (J.) Smith. The ethyl acetate and $n-\mathrm{BuOH}$ extracts had good antitumor activities, consequently leading to the isolation of 23 compounds identified as protocate chaldehyde (1), woodwardinsauremethylester (2), pimpinellin (3), trans-2-coumaric acid (4), physcion (5), ursolic acid (6), sitost-4-en-3-one (7), betulin (8), 3',4',5-trihydroxy-3,7dimethoxyflavone (9), woodwardinic acid (10), sitosterol3-O- $\beta$-D-glucopyranoside(11), sutchuenoside A (12), $\beta$ sitosterol (13), kaempferol-3,7-O- $\alpha$-L-dirhamnoside (14), (-)-epicatchin (15), (+)-catechin hydrate (16), kaempferol (17), asiatic acid (18), 2 $\beta, 3 \beta, 23$-tihydroxy-12-oleanen28-oic acid (19), crassirhizomoside A (20), kaempferol3-O-(3-O-acetyl- $\alpha$-L-rhamnopyranoside) (21), $2 \alpha, 3 \alpha, 24-$

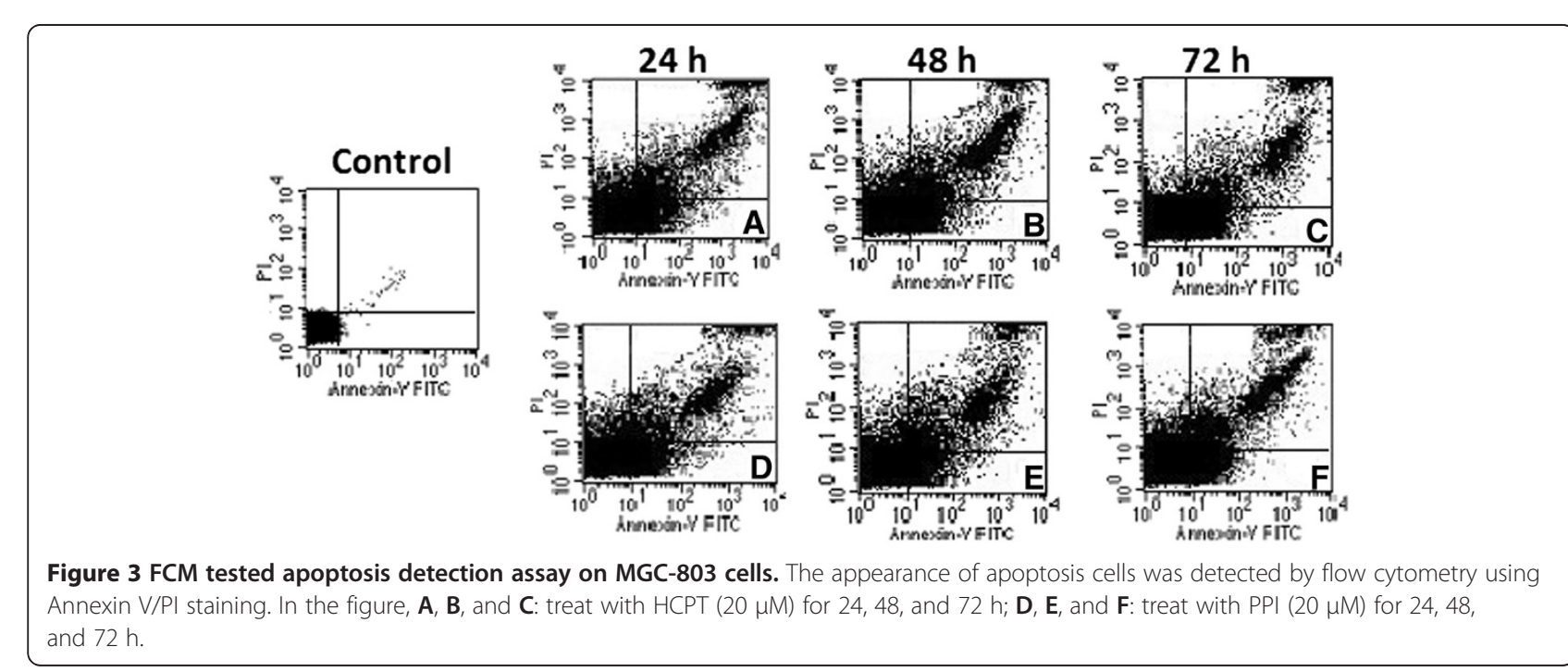


trihydroxyurs-12-en-28-oic acid (22), and kaempferol-3O- $\alpha$-L-rhamnopyranoside-7-O- $\alpha$-L-rhamopyranoside (23). All compounds were isolated from Cyrtomium fortumei (J.) Smith for the first time. The inhibitory activities of these compounds were investigated on tumor cells MGC803, PC3, and A375 in vitro by MTT assay, and the results showed that some of the compounds exhibited moderate antiproliferative activities. PPI showed potent activities on MGC-803, PC3, and A375 cell lines, with the $\mathrm{IC}_{50}$ values of $14.4 \pm 0.3 \mu \mathrm{M}, 20.4 \pm 0.5 \mu \mathrm{M}$, and $29.2 \pm 0.6 \mu \mathrm{M}$, respectively. The apoptosis inducing activities of PPI on MGC-803 cell lines were investigated through AO/EB staining, Hoechst 33258 staining, TUNEL and FCM assay. The results demonstrated that PPI could induce cell apoptosis of MGC-803 cells. Further studies of the specific mechanisms of the compound on human malignant tumors are currently underway.

\section{Experimental}

\section{General procedures and reagents}

The melting points of the products were determined using an XT-4 binocular microscope (Beijing Tech Instrument Co. Ltd., Beijing, China). Infrared spectra were recorded on a Bruker VECTOR22 spectrometer in KBr disks. ${ }^{1} \mathrm{H}-\mathrm{NMR}$ and ${ }^{13} \mathrm{C}$-NMR were recorded using a JEOL-ECX500 spectrometer at $22^{\circ} \mathrm{C}$, with tetramethylsilane as the internal standard and $\mathrm{CDCl}_{3}, \mathrm{DMSO}-d_{6}$, $\mathrm{CD}_{3} \mathrm{COCD}_{3}$, or $\mathrm{CD}_{3} \mathrm{OD}$ as the solvent. Column chromatography was performed using silica gel (200-300 meshes) (Qingdao Marine Chemistry Co., Qingdao, China) and silica gel H (Qingdao Marine Chemistry Co., Qingdao, China), Sephadex LH-20 (GE Healthcare BioSciences AB, Uppsala, Sweden), HP-20 (Mitsubishi Chemical Corp., Toukyu Met, Japan), YMC RP-18 (YMC Corp., Kyoto, Japan) and MCI-gel CHP 20P (Mitsubishi Chemical Corp., Toukyu Met, Japan). All other chemicals were of analytical reagent grade and used without further purification.

\section{Plant materials}

Fresh samples of Cyrtomium fortumei were collected from Longli, Guizhou Province in China, in August 2011. Prof. Qingde Long, Department of Medicine, Guiyang Medical University, identified the plant material. A voucher specimen was deposited at Guiyang Medical University, Guiyang, China.

\section{Extraction and isolation}

Dried rhizomes of Cyrtomium fortumei (J.) Smith $(10 \mathrm{~kg})$ were cut into pieces and extracted with $80 \%$ $\mathrm{EtOH}(3 \times 40 \mathrm{~L})$ under reflux, $6 \mathrm{~h}$ for the first time, $3 \mathrm{~h}$ for the second time and $1 \mathrm{~h}$ for the last time. The combined EtOH extracts were evaporated to dryness to yield a dried $\mathrm{EtOH}$ extract (424 g). The extract was suspended in water and then extracted with petroleum ether (10 $\mathrm{L} \times 3$ times), ethyl acetate $(10 \mathrm{~L} \times 3$ times $)$ and $n$ $\mathrm{BuOH}(10 \mathrm{~L} \times 3$ times) respectively. The organic ethyl acetate extract (95 g) was subjected to CC on silica gel (200-300 mesh) eluted with a gradient of petroleum ether-EtOAc $(20 / 1,10 / 1,5 / 1,2 / 1$ and $1 / 1, v / v)$, and finally a mixture of chloroform and methanol (10/1, 5/1 and $1 / 1, v / v$, respectively) to get 10 fractions, namely, fraction 1-10. The fractions were monitored by TLC. Fraction 3 (10 g) was applied to a silica gel (200-300 mesh) column eluted with petroleum ether-EtOAc (10:1 to $1: 1)$ to yield Protocate chaldehyde $(\mathbf{1}, 30 \mathrm{mg})$, Woodwardinsauremethylester $(2,13 \mathrm{mg})$ and yield 7 fractions, namely, Fraction $1^{\prime}-7^{\prime}$. Fractions $2^{\prime}$ and $5^{\prime}$ were purified using PTLC to yield Pimpinellin (3, $25 \mathrm{mg}$ ), Trans-2coumaric acid (4, $13 \mathrm{mg})$, and Physcion (5, $18 \mathrm{mg})$. Fractions $6^{\prime}$ and $7^{\prime}$ was separated using silica gel (300-400 mesh) eluted with petroleum ether-EtOAc (10:1) to yield Ursolic acid (6, $23 \mathrm{mg})$, Sitost-4-en-3-one (7, $14 \mathrm{mg})$, and Betulin (8, $18 \mathrm{mg})$. Fraction 5 (8 g) was applied to a silica gel $\mathrm{H}$ column eluted with $\mathrm{CHCl}_{3}-\mathrm{MeOH}$ (10:1 to $5: 1$ ) to yield a yellow powder ( $3 \mathrm{~g}$ ), and purified using a Sephadex LH-20 column eluted with $\mathrm{MeOH}$ to yield 3',4',5-Trihydroxy-3,7-dimethoxyflavone (9, $15 \mathrm{mg})$. The yellow powder was purified using silica gel repeatedly, to yield Woodwardinic acid (10, $32 \mathrm{mg})$, Sitosterol-3-O- $\beta$ D-glucopyranoside $(\mathbf{1 1}, 43 \mathrm{mg})$, and Sutchuenoside A $(12,16 \mathrm{mg})$. Fraction $6(13 \mathrm{~g})$ was applied to a silica gel $\mathrm{H}$ column eluted with $\mathrm{CHCl}_{3}-\mathrm{MeOH}(8: 1$ to $2: 1)$ to yield 2 fractions, namely fraction $\mathrm{A}$ and $\mathrm{B}$. Fraction A was purified using a Sephadex LH-20 column eluted with $\mathrm{CHCl}_{3}-\mathrm{MeOH}(1: 1)$ to yield $\beta$-sitosterol $(13,24 \mathrm{mg})$, and kaempferol-3,7-O- $\alpha$-L-dirhamnoside (14, 25 mg). Fraction $\mathrm{B}$ was recrystallized with acetone to give compound (-)-Epicatchin (15, $13 \mathrm{mg})$.

The $n$ - $\mathrm{BuOH}$ extract (110 g) was suspended in $\mathrm{H}_{2} \mathrm{O}$, adsorbed on an MCI-gel column (500 g), and eluted using mixtures of $\mathrm{H}_{2} \mathrm{O}$ and $\mathrm{MeOH}$ starting with 20\% $\mathrm{MeOH}(v / v)$ to $100 \% \mathrm{MeOH}$ in $10 \%$ increments $(2.5 \mathrm{~L}$ each fraction) to afford a total of 6 fractions, namely fraction 11-16. The fractions were also monitored by RP-TLC. Fraction 12 (6 g) was decolorized and separated on MCI-gel eluted with $50-70 \% \mathrm{MeOH}-\mathrm{H}_{2} \mathrm{O}$ to yield (+)-Catechin hydrate (16, $30 \mathrm{mg})$ and Kaempferol (17, $12 \mathrm{mg})$. Fraction 13 (12 g) was further chromatographed on a YMC RP-18 column $(50 \mu \mathrm{m})$ and eluted using a $\mathrm{MeOH}-\mathrm{H}_{2} \mathrm{O}$ gradient solvent system (50:50 to 90:10) to yield Asiatic acid (18, $14 \mathrm{mg}), 2 \beta, 3 \beta, 23$-tihydroxy-12oleanen-28-oic acid (19, $16 \mathrm{mg})$, and a yellow powder (2 g). The yellow powder was further purified over a Sephadex $\mathrm{LH}-20$ column and eluted with $\mathrm{CHCl}_{3}-\mathrm{MeOH}$ (1:1) to yield Crassirhizomoside A (20, $22 \mathrm{mg})$ and subfraction (A1-A4). Fraction A2 was separated using silica gel (300-400 mesh) and purified through Sephadex LH- 
20 to yield Kaempferol-3-O-(3-O-acetyl- $\alpha$-L-rhamnopyranoside) (21, $14 \mathrm{mg})$. Fraction A3 was purified with silica gel (300-400 mesh) to yield $2 \alpha, 3 \alpha, 24$-trihydroxyurs-12-en-28-oic acid (22, 16 mg). Fraction 14 (11 g) were separated using HP-20 resin eluted with $60 \%$ $90 \% \mathrm{MeOH}-\mathrm{H}_{2} \mathrm{O}$ and purified using a Sephadex LH20 column eluted with $\mathrm{MeOH}$ to yield Kaempferol-3O- $\alpha$-L-rhamnopyranoside-7-O- $\alpha$-L-rhamopyranoside (23, $23 \mathrm{mg})$.

All spots on TLC were visualized by heating silica gel plates sprayed with 10\% Phosphomolybdic acid hydrate in $\mathrm{EtOH}$ and $1 \% \mathrm{FeCl}_{3}$ in $\mathrm{EtOH}$.

\section{Spectroscopic data}

Protocate chaldehyde (1). Yellow powder, $\mathrm{mp} 151-153^{\circ} \mathrm{C}$. ${ }^{1} \mathrm{H}-\mathrm{NMR}\left(\mathrm{CD}_{3} \mathrm{OD}, 500 \mathrm{MHz}\right)$ 8: $9.63(1 \mathrm{H}, \mathrm{s}, \mathrm{CHO}), 7.23$ $(2 \mathrm{H}, \mathrm{m}, \mathrm{H}-6,-2), 6.86(1 \mathrm{H}, \mathrm{d}, J=5 \mathrm{~Hz}, \mathrm{H}-5) .{ }^{13} \mathrm{C}-\mathrm{NMR}$ $\left(\mathrm{CD}_{3} \mathrm{OD}, 125 \mathrm{MHz}\right)$ 8: 192.1 (-CHO), 152.4 (C-4), 145.7 (C-3), 129.3 (C-1), 125.49 (C-6), 115.0 (C-5), 114.3 (C-2). The above data were identical to the literature data [31].

Woodwardinsauremethylester (2). White powder, mp 201-203 ${ }^{\circ} \mathrm{C}$. IR $\left(\mathrm{KBr}, \mathrm{cm}^{-1}\right) v_{\text {max }}: 3480,1738,1630,890$. ${ }^{1} \mathrm{H}-\mathrm{NMR}\left(\mathrm{CDCl}_{3}, 500 \mathrm{MHz}\right) \delta: 4.75(2 \mathrm{H}, \mathrm{s}, \mathrm{H}-30)$, $3.67\left(3 \mathrm{H}, \mathrm{s}, \mathrm{COOCH}_{3}\right), 1.63(3 \mathrm{H}, \mathrm{s}, \mathrm{Me}), 1.17(3 \mathrm{H}, \mathrm{s}$, $\mathrm{Me}), 0.99$ (3H, s, Me), 0.85 (3H, s, Me), 0.83 (3H, s, Me), $0.61(3 \mathrm{H}, \mathrm{s}, \mathrm{Me}) .{ }^{13} \mathrm{C}-\mathrm{NMR}\left(\mathrm{CDCl}_{3}, 125 \mathrm{MHz}\right) \delta: 181.2$ $\left(\underline{\mathrm{COOCH}}{ }_{3}\right), 148.8(\mathrm{C}-30), 109.8$ (C-22), $66.4(\mathrm{C}-3), 57.3$ $\left(\mathrm{COOCH}_{3}\right), 19.7(\mathrm{C}-29), 19.5$ (C-26), 17.8 (C-27), 16.6 (C-28), 16.3 (C-25), 16.0 (C-24), The above data were identical to the literature data [32].

Pimpinellin (3). Pale yellow powder, $\mathrm{mp} 118-120^{\circ} \mathrm{C}$. IR $\left(\mathrm{KBr}, \mathrm{cm}^{-1}\right) v_{\max }: 1724,1613,1576,1060 .{ }^{1} \mathrm{H}-\mathrm{NMR}$ $\left(\mathrm{CDCl}_{3}, 500 \mathrm{MHz}\right) \delta: 8.07(1 \mathrm{H}, \mathrm{d}, J=10 \mathrm{~Hz}, \mathrm{H}-4), 7.64$ $(1 \mathrm{H}, \mathrm{d}, J=1.5 \mathrm{~Hz}, \mathrm{H}-12), 7.05(1 \mathrm{H}, \mathrm{d}, J=3 \mathrm{~Hz}, \mathrm{H}-11)$, $6.34(1 \mathrm{H}, \mathrm{d}, J=10 \mathrm{~Hz}, \mathrm{H}-3), 4.12\left(3 \mathrm{H}, \mathrm{s}, \mathrm{OCH}_{3}\right), 4.01$ $\left(3 \mathrm{H}, \mathrm{s}, \mathrm{OCH}_{3}\right) .{ }^{13} \mathrm{C}-\mathrm{NMR}\left(\mathrm{CD}_{3} \mathrm{OD}, 125 \mathrm{MHz}\right) \delta: 160.9$ (C-2), 149.8 (C-7), 145.4 (C-12), 144.4 (C-9), 143.2 (C-5), 140.0 (C-4), 135.2 (C-6), 114.2 (C-3), 113.8 (C-8), 109.5 (C-10), $104.3(\mathrm{C}-11), 62.4\left(\mathrm{OCH}_{3}\right), 61.3\left(\mathrm{OCH}_{3}\right)$. The above data were identical to the literature data [33].

Trans-2-coumaric acid (4). White powder, mp 189$191^{\circ} \mathrm{C} .{ }^{1} \mathrm{H}-\mathrm{NMR}\left(\mathrm{CD}_{3} \mathrm{OD}, 500 \mathrm{MHz}\right) \delta: 7.99(1 \mathrm{H}, \mathrm{d}, J=$ $\left.1.5 \mathrm{~Hz}, \mathrm{H}-1^{\prime}\right), 7.19(1 \mathrm{H}, \mathrm{m}, \mathrm{H}-4), 6.94(1 \mathrm{H}, \mathrm{m}, \mathrm{H}-4), 6.86$ $(1 \mathrm{H}, \mathrm{m}, \mathrm{H}-3), 6.57\left(1 \mathrm{H}, \mathrm{d}, J=2 \mathrm{~Hz}, \mathrm{H}-2^{\prime}\right) .{ }^{13} \mathrm{C}-\mathrm{NMR}$ $\left(\mathrm{CD}_{3} \mathrm{OD}, 125 \mathrm{MHz}\right) \delta: 168.0(\mathrm{C}=\mathrm{O}), 156.6(\mathrm{C}-2), 140.5$ (C-1'), 131.5 (C-4), 128.9 (C-6), 121.5 (C-1), 120.0 (C-5), 117.9 (C-3), $116.2\left(\mathrm{C}-2^{\prime}\right)$. The above data were identical to the literature data [34].

Ursolic acid (6). White powder, mp $257-259^{\circ} \mathrm{C}$. IR $\left(\mathrm{KBr}, \mathrm{cm}^{-1}\right) v_{\max }: 3444,2928,2868,1683,1458,1028$. ${ }^{1} \mathrm{H}-\mathrm{NMR}\left(\mathrm{CD}_{3} \mathrm{OD}, 500 \mathrm{MHz}\right) \delta: 0.78\left(\mathrm{CH}_{3}, \mathrm{~d}, J=10 \mathrm{~Hz}\right.$, $\mathrm{H}-29), 0.84\left(\mathrm{CH}_{3}, \mathrm{~d}, J=10 \mathrm{~Hz}, \mathrm{H}-30\right), 0.90\left(\mathrm{CH}_{3}, \mathrm{~s}, \mathrm{H}-\right.$ 23), $0.92\left(\mathrm{CH}_{3}, \mathrm{~s}, \mathrm{H}-26\right), 0.97\left(\mathrm{CH}_{3}, \mathrm{~s}, \mathrm{H}-25\right), 1.09\left(\mathrm{CH}_{3}\right.$, s, H-27), $3.20(1 \mathrm{H}, \mathrm{d}, J=5 \mathrm{~Hz}, \mathrm{H}-3), 5.2(1 \mathrm{H}, \mathrm{t}, J=$ $1.5 \mathrm{~Hz}, \mathrm{H}-12) .{ }^{13} \mathrm{C}-\mathrm{NMR}\left(\mathrm{CD}_{3} \mathrm{OD}, 125 \mathrm{MHz}\right) \delta: 180.1$ (C-28), 138.3 (C-13), 125.6 (C-12), 78.1 (C-3), 55.4 (C5), 53.1 (C-18), 41.9 (C-14), 39.5 (C-8), 39.1 (C-19), 38.9 (C-1), 38.7 (C-4), 38.5 (C-20), 36.8 (C-10), 36.7 (C-22), 33.0 (C-7), 30.4 (C-21), 27.9 (C-23), 27.4 (C-15), 26.6 (C-2), 24.2 (C-16), 23.0 (C-11), 22.7 (C-27), 21.2 (C-30), 18.3 (C-6), 16.5 (C-26), 16.2 (C-29), 14.7 (C-25), 14.6 (C-24). The above data were identical to the literature data [35].

Sitost-4-en-3-one (7). White crystalline, mp $90-92^{\circ} \mathrm{C}$. IR $\left(\mathrm{KBr}, \mathrm{cm}^{-1}\right) v_{\max }: 2940,1688,1390,867 .{ }^{1} \mathrm{H}-\mathrm{NMR}$ $\left(\mathrm{CDCl}_{3}, 500 \mathrm{MHz}\right) \delta: 5.58(1 \mathrm{H}, \mathrm{d}, J=1.5 \mathrm{~Hz}, \mathrm{H}-4), 1.07$ (3H, s, H-19), 0.88 (3H, m, H-29), 0.71 (3H, s, H-18). ${ }^{13} \mathrm{C}-\mathrm{NMR}\left(\mathrm{CD}_{3} \mathrm{OD}, 125 \mathrm{MHz}\right) \delta: 199.6$ (C-3), 171.74 (C5), 123.68 (C-4), 55.9 (C-17), 55.8 (C-14), 53.7 (C-9), 45.8 (C-24), 42.3 (C-13), 39.5 (C-12), 38.6 (C-10), 36.1 (C-20), 35.6 (C-8), 35.5 (C-1), 33.9 (C-22), 33.9 (C-2), 32.9 (C-6), 32.0 (C-7), 29.1 (C-25), 28.1 (C-16), 26.0 (C23), 24.1 (C-15), 23.0 (C-28), 21.0 (C-11), 19.8 (C-26), 19.0 (C-27), 18.7 (C-21), 17.3 (C-19), 11.9 (C-29), 11.9 (C-18). The above data were identical to the literature data [36].

Betulin (8). White powder, mp 234-236 ${ }^{\circ} \mathrm{C}$. IR ( $\mathrm{KBr}$, $\left.\mathrm{cm}^{-1}\right) v_{\max }: 3498,2941,1456,1033 .{ }^{1} \mathrm{H}-\mathrm{NMR}\left(\mathrm{CDCl}_{3}\right.$, $500 \mathrm{MHz}) \delta: 3.79(1 \mathrm{H}, \mathrm{d}, J=10 \mathrm{~Hz}, \mathrm{H}-3), 4.67(1 \mathrm{H}, \mathrm{s}, \mathrm{H}-$ 29), 4.56 (1H, s, H-29), 3.77 (1H, d, J=5 Hz, H-28), 3.31 $(1 \mathrm{H}, \mathrm{d}, J=10 \mathrm{~Hz}, \mathrm{H}-28), 3.18(1 \mathrm{H}, \mathrm{d}, J=5.5 \mathrm{~Hz}, \mathrm{H}-3)$, 1.66 (3H, s, H-30). ${ }^{13} \mathrm{C}-\mathrm{NMR}\left(\mathrm{CDCl}_{3}, 125 \mathrm{MHz}\right) \delta: 150.5$ (C-20), 109.7 (C-29), 79.0 (C-3), 60.6 (C-28), 55.3 (C-5), 50.4 (C-9), 48.8 (C-18), 47.8 (C-17, 19), 42.7 (C-14), 40.9 (C-8), 38.9 (C-4), 38.7 (C-1), 37.4 (C-13), 37.2 (C-10), 34.2 (C-7), 34.0 (C-22), 29.8 (C-21), 29.2 (C-16), 28.0 (C23), 27.4 (C-2), 27.1 (C-15), 25.3 (C-12), 20.8 (C-11), 19.1 (C-30), 18.4 (C-6), 16.1 (C-25), 16.0 (C-26), 15.4 (C24), 14.8 (C-27). The above data were identical to the literature data [37].

$3^{\prime}, 4^{\prime}, 5$-Trihydroxy-3,7-dimethoxyflavone (9). Yellow powder, mp 233-235 ${ }^{\circ} \mathrm{C}$. IR $\left(\mathrm{KBr}, \mathrm{cm}^{-1}\right) v_{\max } 3455,1642,1531$. ${ }^{1} \mathrm{H}-\mathrm{NMR}\left(\mathrm{CD}_{3} \mathrm{OD}, 500 \mathrm{MHz}\right) \delta: 7.47(1 \mathrm{H}, \mathrm{d}, J=3 \mathrm{~Hz}$, $\left.\mathrm{H}-2^{\prime}\right), 6.85\left(1 \mathrm{H}, \mathrm{d}, J=10 \mathrm{~Hz}, \mathrm{H}-5^{\prime}\right), 6.45(1 \mathrm{H}, \mathrm{d}, J=2.5 \mathrm{~Hz}$, $\mathrm{H}-8), 6.35(1 \mathrm{H}, \mathrm{d}, J=3 \mathrm{~Hz}, \mathrm{H}-6), 3.86\left(3 \mathrm{H}, \mathrm{s}, \mathrm{OCH}_{3}\right) 3.73$ $\left(3 \mathrm{H}, \mathrm{s}, \mathrm{OCH}_{3}\right) .{ }^{13} \mathrm{C}-\mathrm{NMR}\left(\mathrm{CD}_{3} \mathrm{OD}, 125 \mathrm{MHz}\right) \delta: 174.8$ (C-4), 162.4 (C-7), 161.1 (C-9), 158.8 (C-5), 154.8 (C-2), $148.1\left(\mathrm{C}-4^{\prime}\right), 145.0\left(\mathrm{C}-3^{\prime}\right), 140.0(\mathrm{C}-3), 121.7\left(\mathrm{C}-1^{\prime}\right), 120.6$ (C-6), $115.0\left(\mathrm{C}-2^{\prime}\right), 114.9$ (C-5'), 107.3 (C-10), 95.7 (C-6), 94.6 (C-8), $58.8\left(\mathrm{OCH}_{3}\right), 55.1\left(\mathrm{OCH}_{3}\right)$. The above data were identical to the literature data [38].

Woodwardinic acid (10). White powder, mp $242-244^{\circ} \mathrm{C}$. IR $\left(\mathrm{KBr}, \mathrm{cm}^{-1}\right) v_{\max }: 3490,1709,1635,886 .{ }^{1} \mathrm{H}-\mathrm{NMR}$ $\left(\mathrm{DMSO}-d_{6}, 500 \mathrm{MHz}\right) \delta: 4.75(2 \mathrm{H}, \mathrm{s}, \mathrm{H}-30), 1.69(3 \mathrm{H}, \mathrm{s}$, $\mathrm{Me}), 1.24$ (3H, s, Me), 1.10 (3H, s, Me), 0.95 (3H, s, Me), $0.92(3 \mathrm{H}, \mathrm{s}, \mathrm{Me}), 0.69$ (3H, s, Me). ${ }^{13} \mathrm{C}-\mathrm{NMR}$ (DMSO- $d_{6}$, $125 \mathrm{MHz}$ ) 8: 180.3 (C-23), 148.3 (C-30), 110.3 (C-22), 
65.7 (C-3), 21.2 (C-29), 18.9 (C-27), 18.4 (C-26), 16.3 (C28), 16.0 (C-24), 16.0 (C-25). The above data were identical to the literature data [39].

Sutchuenoside A (12). Pale yellow amorphous powder, mp $211-213^{\circ} \mathrm{C}$. IR $\left(\mathrm{KBr}, \mathrm{cm}^{-1}\right) v_{\text {max }}: 3455,1701,1623 .{ }^{1} \mathrm{H}-$ NMR $\left(\mathrm{CD}_{3} \mathrm{OD}, 500 \mathrm{MHz}\right) \delta: 7.74\left(2 \mathrm{H}, \mathrm{d}, J=9 \mathrm{~Hz}, \mathrm{H}-2^{\prime}\right.$, $\left.-6^{\prime}\right), 6.94\left(2 \mathrm{H}, \mathrm{d}, J=9 \mathrm{~Hz}, \mathrm{H}-3^{\prime},-5^{\prime}\right), 6.71(1 \mathrm{H}, \mathrm{d}, J=1 \mathrm{~Hz}$, $\mathrm{H}-8), 6.45(1 \mathrm{H}, \mathrm{d}, J=1 \mathrm{~Hz}, \mathrm{H}-6), 5.57\left(1 \mathrm{H}, \mathrm{br} \mathrm{s}, \mathrm{H}-1^{\prime \prime}\right)$, $5.50\left(1 \mathrm{H}, \mathrm{s}, 2\right.$ "'-OH), $4.52\left(1 \mathrm{H}, \mathrm{s}, 3^{\prime \prime \prime}-\mathrm{OH}\right), 4.19(1 \mathrm{H}, \mathrm{br} \mathrm{s}$, H-2"), $3.92\left(1 \mathrm{H}\right.$, br s, H-2"'), $3.82\left(1 \mathrm{H}, \mathrm{m}, \mathrm{H}-3{ }^{\prime \prime}\right), 3.58$ $\left(1 \mathrm{H}, \mathrm{m}, \mathrm{H}-3^{\prime \prime \prime}\right), 3.45$ (1H, m, H-5"'), 3.21-3.25 (2H, m, H4"', -5"), 2.08 (3H, s, Ac), 1.25 (3H, d, $J=6.5 \mathrm{~Hz}, \mathrm{Me}-6{ }^{\prime \prime}$ ), $0.77\left(3 \mathrm{H}, \mathrm{d}, J=5 \mathrm{~Hz}, \mathrm{Me}-6^{\prime \prime}\right) .{ }^{13} \mathrm{C}-\mathrm{NMR}\left(\mathrm{CD}{ }_{3} \mathrm{OD}\right.$, $125 \mathrm{MHz})$ 8: $178.3(\mathrm{C}-4), 171.0\left(\mathrm{COCH}_{3}\right), 162.2(\mathrm{C}-7)$, 161.6 (C-5), 160.5 (C-4'), 158.6 (C-2), 156.8 (C-9), 134.5 (C-3), $130.7\left(\mathrm{C}-3^{\prime},-5^{\prime}\right), 120.9\left(\mathrm{C}-1^{\prime}\right), 115.2\left(\mathrm{C}-2^{\prime},-6^{\prime}\right), 106.2$ (C-10), 101.2 (C-1'), 99.3 (C-6), 98.5 (C-1"'), 94.3 (C-8), 73.5 (C-4"), 72.2 (C-4"'), 70.7 (C-3"'), 70.3 (C-5"'), 70.3 (C-2"), 69.9 (C-2"'), 68.6 (C-5"), 68.3 (C-3"), 19.6 $\left(\mathrm{COCH}_{3}\right), 17.0(\mathrm{C}-6 "), 16.2\left(\mathrm{C}-6^{\prime \prime}\right)$. The above data were identical to the literature data [40].

Kaempferol-3,7-O- $\alpha$-L-dirhamnoside (14). Light yellow crystals, mp $175-177^{\circ} \mathrm{C}$. IR $\left(\mathrm{KBr}, \mathrm{cm}^{-1}\right) v_{\max }: 3347$, 2912, 1613, 876. ${ }^{1} \mathrm{H}-\mathrm{NMR}\left(\mathrm{CD}_{3} \mathrm{OD}, 500 \mathrm{MHz}\right)$ 8: 7.78 $(2 \mathrm{H}, \mathrm{d}, J=8.5 \mathrm{~Hz}), 6.92(2 \mathrm{H}, \mathrm{d}, J=8.5 \mathrm{~Hz}), 6.70(1 \mathrm{H}, \mathrm{d}$, $J=2 \mathrm{~Hz}), 6.44(1 \mathrm{H}, \mathrm{d}, J=2.5 \mathrm{~Hz}), 5.54\left(1 \mathrm{H}, \mathrm{br} \mathrm{s}, \mathrm{H}-1^{\prime \prime}\right)$, $5.38\left(1 \mathrm{H}\right.$, br s, $\left.2{ }^{\prime \prime}-\mathrm{OH}\right), 1.24\left(3 \mathrm{H}, \mathrm{d}, J=6 \mathrm{~Hz}, \mathrm{Me}-6^{\prime \prime \prime}\right)$, $0.91\left(3 \mathrm{H}, \mathrm{d}, J=5.5 \mathrm{~Hz}, \mathrm{Me}-6{ }^{\prime \prime \prime}\right) .{ }^{13} \mathrm{C}-\mathrm{NMR}\left(\mathrm{CD}_{3} \mathrm{OD}\right.$, $125 \mathrm{MHz}) \delta$ : $178.4(\mathrm{C}-4), 162.2(\mathrm{C}-7), 160.4\left(\mathrm{C}-4^{\prime}\right), 158.4$ (C-2), 156.7 (C-9), 135.1 (C-3), 162.2 (C-5), 99.2 (C-6), $94.2(\mathrm{C}-8), 121.0\left(\mathrm{C}-1^{\prime}\right), 115.2\left(\mathrm{C}-2^{\prime},-6^{\prime}\right), 130.7\left(\mathrm{C}-3^{\prime},-5^{\prime}\right)$, 106.2 (C-10), 102.1 (C-1"), 98.5 (C-1"'), 72.2 (C-4"), 71.8 (C-4"'), 70.7 (C-2"), 70.7 (C-5"'), 70.7 (C-3"'), 70.5 (C-2"'), 70.3 (C-5"), 69.9 (C-3"), 16.7 (C-6"'), 16.3 $\left(\mathrm{C}-6^{\prime \prime}\right)$. The above data were identical to the literature data [41].

(-)-Epicatchin (15). White powder, mp 222-224 ${ }^{\circ} \mathrm{C}$. IR $\left(\mathrm{KBr}, \mathrm{cm}^{-1}\right) v_{\max } 3440,1622,1461,1289 ;{ }^{1} \mathrm{H}$ NMR $\left(\mathrm{CD}_{3} \mathrm{OD}, 500 \mathrm{MHz}\right) \delta: 6.79\left(1 \mathrm{H}, \mathrm{d}, J=5 \mathrm{~Hz}, \mathrm{H}-6^{\prime}\right), 6.75$ $\left(1 \mathrm{H}, \mathrm{d},=15 \mathrm{~Hz}, \mathrm{H}-2^{\prime}\right), 6.70(1 \mathrm{H}, \mathrm{d}, J=1.5 \mathrm{~Hz}, \mathrm{H}-5), 5.93$ $(1 \mathrm{H}, \mathrm{d}, J=3 \mathrm{~Hz}, \mathrm{H}-8), 5.84(1 \mathrm{H}, \mathrm{d}, J=1.5 \mathrm{~Hz}, \mathrm{H}-6), 4.80$ $(1 \mathrm{H}, \mathrm{s}, \mathrm{H}-2), 2.85(1 \mathrm{H}, \mathrm{dd}, J=10 \mathrm{~Hz}, 12.5 \mathrm{~Hz}, \mathrm{H}-3), 2.48$ $(1 \mathrm{H}, \mathrm{dd}, J=12 \mathrm{~Hz}, 10 \mathrm{~Hz}, \mathrm{H}-4) ;{ }^{13} \mathrm{C}$ NMR $\left(\mathrm{CD}_{3} \mathrm{OD}\right.$, $125 \mathrm{MHz})$ 8: 156.8 (C-9), 156.2 (C-7), 155.5 (C-5), 144.8 $\left(\mathrm{C}-3^{\prime}\right), 144.9\left(\mathrm{C}-4^{\prime}\right), 130.9\left(\mathrm{C}-1^{\prime}\right), 118.0\left(\mathrm{C}-6^{\prime}\right), 114.7(\mathrm{C}-$ 2'), 113.9 (C-5'), 98.7 (C-10), 95.0 (C-6), 94.5 (C-8), 78.5 (C-2), 66.1 (C-3), 27.9 (C-4). The above data were identical to the literature data [42].

(+)-Catechin hydrate (16). White powder, mp 134$136^{\circ} \mathrm{C}$. IR $\left(\mathrm{KBr}, \mathrm{cm}^{-1}\right) v_{\max } 3350,1635,1511 ;{ }^{1} \mathrm{H}-\mathrm{NMR}$ $\left(\mathrm{CD}_{3} \mathrm{OD}, 500 \mathrm{MHz}\right) \delta: 6.81\left(1 \mathrm{H}, \mathrm{d}, J=1 \mathrm{~Hz}, \mathrm{H}-2^{\prime}\right), 6.72$ $\left(1 \mathrm{H}, \mathrm{d}, J=8 \mathrm{~Hz}, \mathrm{H}-6^{\prime}\right), 6.70(1 \mathrm{H}, \mathrm{d}, J=1.5 \mathrm{~Hz}, \mathrm{H}-5), 5.90$ $(1 \mathrm{H}, \mathrm{d}, J=3 \mathrm{~Hz}, \mathrm{H}-8), 5.82(1 \mathrm{H}, \mathrm{d}, J=2 \mathrm{~Hz}, \mathrm{H}-6), 4.54$ $(1 \mathrm{H}, \mathrm{d}, J=7 \mathrm{~Hz}, \mathrm{H}-2), 2.83(1 \mathrm{H}, \mathrm{dd}, J=5,15 \mathrm{~Hz}, \mathrm{H}-3)$,
$2.47(1 \mathrm{H}, \mathrm{dd}, J=14,10 \mathrm{~Hz}, \mathrm{H}-4) \cdot{ }^{13} \mathrm{C}-\mathrm{NMR}\left(\mathrm{CD}_{3} \mathrm{OD}\right.$, $125 \mathrm{MHz})$ 8: 156.5 (C-7), 156.2 (C-9), 155.6 (C-5), 144.9 (C-4'), $144.9\left(\mathrm{C}-3^{\prime}\right), 130.8\left(\mathrm{C}-1^{\prime}\right), 118.7\left(\mathrm{C}-6^{\prime}\right), 114.7\left(\mathrm{C}-5^{\prime}\right)$, 113.9 (C-2'), 99.5 (C-10), 94.9 (C-6), 94.1 (C-8), 81.5 (C-2), 67.4 (C-3), $27.2(\mathrm{C}-4)$. The above data were identical to the literature data [43].

Kampferol (17). Yellow powder, mp $279-281^{\circ} \mathrm{C}$. IR $\left(\mathrm{KBr}, \mathrm{cm}^{-1}\right) v_{\max } 3409,1649,1511 ;{ }^{1} \mathrm{H}-\mathrm{NMR}\left(\mathrm{CD}_{3} \mathrm{OD}\right.$, $500 \mathrm{MHz}) \delta: 12.48(1 \mathrm{H}, \mathrm{s}, \mathrm{C}-5-\mathrm{OH}), 7.98(2 \mathrm{H}, \mathrm{d}, J=$ $\left.1.5 \mathrm{~Hz}, \mathrm{H}-2^{\prime}, \mathrm{H}-6^{\prime}\right), 6.88\left(2 \mathrm{H}, \mathrm{d}, J=4 \mathrm{~Hz}, \mathrm{H}-3^{\prime}, \mathrm{H}-5^{\prime}\right)$, $6.35(1 \mathrm{H}, \mathrm{d}, J=1 \mathrm{~Hz}, \mathrm{H}-8), 6.11(1 \mathrm{H}, \mathrm{d}, J=1.5 \mathrm{~Hz}, \mathrm{H}-6)$. ${ }^{13} \mathrm{C}-\mathrm{NMR}$ (CD $\left.{ }_{3} \mathrm{OD}, 125 \mathrm{MHz}\right)$ 8: $175.8(\mathrm{C}-4), 164.1(\mathrm{C}-$ 7), 161.2 (C-9), $159.2\left(\mathrm{C}-4^{\prime}\right), 156.9$ (C-5), $146.2(\mathrm{C}-2)$, $135.8\left(\mathrm{C}-6^{\prime}\right), 129.6\left(\mathrm{C}-2^{\prime}\right), 122.5\left(\mathrm{C}-1^{\prime}\right), 115.5\left(\mathrm{C}-5^{\prime}\right)$, $115.4\left(\mathrm{C}-3^{\prime}\right), 103.3$ (C-10), 98.3 (C-6), 93.7(C-8). The above data were identical to the literature data [44].

Asiatic acid (18). White powder, mp $233-235^{\circ} \mathrm{C}$. IR $\left(\mathrm{KBr}, \mathrm{cm}^{-1}\right) v_{\max }: 3428,3380,1688,1375,920 .{ }^{1} \mathrm{H}-\mathrm{NMR}$ $\left(\mathrm{CD}_{3} \mathrm{OD}, 500 \mathrm{MHz}\right) \delta: 1.06(3 \mathrm{H}, \mathrm{s}, \mathrm{H}-25), 0.99(9 \mathrm{H}, \mathrm{s}$, $\mathrm{H}-24,26,27), 0.90$ (3H, d, $J=8 \mathrm{~Hz}, \mathrm{H}-29), 0.84$ (3H, d, $J$ $=1.5 \mathrm{~Hz}, \mathrm{H}-30) .{ }^{13} \mathrm{C}-\mathrm{NMR}\left(\mathrm{CD}_{3} \mathrm{OD}, 125 \mathrm{MHz}\right) \delta: 179.7$ (C-28), 139.1 (C-13), 125.4 (C-12), 77.9 (C-3), 68.7 (C-2), 66.3 (C-23), 53.4 (C-18), 47.9 (C-17), 47.9 (C-5), 47.7 (C-9), 47.7 (C-1), 43.4 (C-14), 42.3 (C-4), 39.9 (C-8), 39.8 (C-20), 39.3 (C-19), 39.2 (C-10), 37.2 (C-22), 33.0 (C-7), 30.9 (C-21), 28.4 (C-15), 24.7 (C-16), 23.7 (C-11), 23.5 (C-27), 21.2 (C-30), 18.3 (C-6), 17.3 (C-29), 17.3 (C-26), 17.3 (C-25), 14.3 (C-24). The above data were identical to the literature data [45].

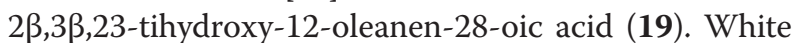
powder, $\mathrm{mp} 212-215^{\circ} \mathrm{C}$. IR $\left(\mathrm{KBr}, \mathrm{cm}^{-1}\right) v_{\max }: 3410-3385$, 1688, 1355. ${ }^{1} \mathrm{H}-\mathrm{NMR}\left(\mathrm{CD}_{3} \mathrm{OD}, 500 \mathrm{MHz}\right) \delta: 5.38(\mathrm{H}, \mathrm{br}$ s, H-12), $3.72(1 \mathrm{H}$, br s, H-3), $3.21(1 \mathrm{H}, \mathrm{dd}, J=4$, $10.5 \mathrm{~Hz}, \mathrm{H}-18), 1.25,1.22,1.11,1.05,0.96(15 \mathrm{H}, \mathrm{s}, \mathrm{H}-25$, 26, 27, 29, 30). ${ }^{13} \mathrm{C}-\mathrm{NMR}\left(\mathrm{CD}_{3} \mathrm{OD}, 125 \mathrm{MHz}\right) \delta: 180.0$ (C-28), 144.6 (C-13), 122.3 (C-12), 74.0 (C-3), 66.0 (C-24), 65.0 (C-2), 53.3 (C-18), 49.2 (C-5), 47.8 (C-9), 46.2 (C-17), 45.0 (C-4), 41.7 (C-1), 41.4 (C-14), 39.2 (C-10), 39.2 (C-8), 39.8 (C-19), 34.0 (C-22), 33.8 (C-21), 33.5 (C-7), 33.0 (C-29), 30.9 (C-20), 28.4 (C-15), 25.9 (C-27), 25.0 (C-16), 23.9 (C-23), 23.9 (C-11), 23.7 (C-30), 17.3 (C-6), 17.0 (C-25), 16.9 (C-26). The above data were identical to the literature data [46].

Crassirhizomoside A (20). Pale yellow amorphous powder, mp $192-194^{\circ} \mathrm{C}$. IR (KBr, $\left.\mathrm{cm}^{-1}\right) v_{\max }: 3428,1745$, 1655, 1610. ${ }^{1} \mathrm{H}-\mathrm{NMR}\left(\mathrm{CD}_{3} \mathrm{OD}, 500 \mathrm{MHz}\right) \delta: 7.73(2 \mathrm{H}, \mathrm{d}$, $\left.J=10 \mathrm{~Hz}, \mathrm{H}-2^{\prime}, 6^{\prime}\right), 6.93\left(2 \mathrm{H}, \mathrm{d}, J=10 \mathrm{~Hz}, \mathrm{H}-3^{\prime}, 5^{\prime}\right), 6.71$ $(1 \mathrm{H}$, br s, H-8), $6.44(1 \mathrm{H}$, br s, H-6) $2.09(3 \mathrm{H}, \mathrm{s}$, $\left.\mathrm{COCH}_{3}-4 "\right), 2.02\left(3 \mathrm{H}, \mathrm{s}, \mathrm{COCH}_{3}-2^{\prime \prime}\right), 1.24(3 \mathrm{H}, \mathrm{d}, J=$ $\left.2.5 \mathrm{~Hz}, \mathrm{H}-66^{\prime \prime}\right), 0.80$ (3H, d, $J=3.5 \mathrm{~Hz}, \mathrm{H}-6$ "). ${ }^{13} \mathrm{C}-\mathrm{NMR}$ $\left(\mathrm{CD}_{3} \mathrm{OD}, 125 \mathrm{MHz}\right)$ 8: 178.0 (C-4), $170.9\left(4{ }^{\prime \prime}-\mathrm{COCH}_{3}\right)$, $170.8\left(2 "-\mathrm{COCH}_{3}\right), 162.2$ (C-5), $162.2\left(\mathrm{C}-4^{\prime}\right), 161.6$ (C-7), 160.6(C-2), 156.7 (C-9), 133.9 (C-3), 130.6 (C-6'), $130.6\left(\mathrm{C}-2^{\prime}\right), 120.7\left(\mathrm{C}-1^{\prime}\right), 115.3\left(\mathrm{C}-5^{\prime}\right), 115.3\left(\mathrm{C}-3^{\prime}\right)$, 
106.1 (C-10), 100.5 (C-6), 99.3 (C-1"), 98.5 (C-1"'), 94.3 (C-8), 73.3 (C-4"), 73.3 (C-4"'), 73.3 (C-2"), 72.2 (C-3"), 69.9 (C-5"'), 69.9 (C-2"'), 68.3 (C-5"), 67.0 (C-3"), 19.5 (4" - $\left.\mathrm{COCH}_{3}\right), 19.5\left(2^{\prime \prime}-\mathrm{COCH}_{3}\right), 16.7\left(\mathrm{C}-6^{\prime \prime \prime}\right), 16.2(\mathrm{C}-6 ")$. The above data were identical to the literature data [47].

Kaempferol-3-O-(3-O-acetyl- $\alpha$-L-rhamnopyranoside) (21). Pale yellow amorphous powder, $\mathrm{mp} 181-183^{\circ} \mathrm{C}$. IR $\left(\mathrm{KBr}, \mathrm{cm}^{-1}\right) \quad v_{\max }: 3398,1744,1603,994 .{ }^{1} \mathrm{H}-\mathrm{NMR}$ $\left(\mathrm{CD}_{3} \mathrm{OD}, 500 \mathrm{MHz}\right) \delta: 7.70\left(2 \mathrm{H}, \mathrm{d}, J=8 \mathrm{~Hz}, \mathrm{H}-2^{\prime}, 6^{\prime}\right)$, $6.91\left(2 \mathrm{H}, \mathrm{d}, J=5 \mathrm{~Hz}, \mathrm{H}-3^{\prime}, 5^{\prime}\right), 6.34(1 \mathrm{H}, \mathrm{d}, J=2 \mathrm{~Hz}, \mathrm{H}-$ 8), $6.20(1 \mathrm{H}, \mathrm{d}, J=2 \mathrm{~Hz}, \mathrm{H}-6), 5.45(1 \mathrm{H}, \mathrm{d}, J=2.5 \mathrm{~Hz}, \mathrm{H}-$ $\left.1^{\prime \prime}\right), 4.40\left(1 \mathrm{H}, \mathrm{m}, \mathrm{H}-2\right.$ "), $2.02\left(3 \mathrm{H}, \mathrm{s}, \mathrm{COOC \textrm {CH } _ { 3 }}\right) .{ }^{13} \mathrm{C}-$ NMR (CD $\left.{ }_{3} \mathrm{OD}, 125 \mathrm{MHz}\right)$ 8: 159.1 (C-2), 135.3 (C-3), $179.1(\mathrm{C}-4), 172.5\left(\mathrm{COCH}_{3}\right), 165.2(\mathrm{C}-7), 162.4\left(\mathrm{C}-4^{\prime}\right)$, 160.9 (C-5), $158.1(\overline{\mathrm{C}}-9), 131.6\left(\mathrm{C}-2^{\prime}, 6^{\prime}\right), 122.2\left(\mathrm{C}-1^{\prime}\right)$, $116.3\left(\mathrm{C}-3^{\prime}, 5^{\prime}\right), 106.0$ (C-10), $102.1\left(\mathrm{C}-1^{\prime \prime}\right), 100.0$ (C-6), 95.0 (C-8), 74.7 (C-3"), 71.3 (C-5"), 70.0 (C-4"), 69.0 (C-2"), $21.5\left(\mathrm{COCH}_{3}\right), 17.7(\mathrm{C}-6 ")$. The above data were identical to the literature data [48].

$2 \alpha, 3 \alpha, 24$-trihydroxyurs-12-en-28-oic acid (22). White powder, mp 204-206 ${ }^{\circ} \mathrm{C}$. IR $\left(\mathrm{KBr}, \mathrm{cm}^{-1}\right) v_{\max }: 3420-3390$, 1690, 1365, 910. ${ }^{1} \mathrm{H}-\mathrm{NMR}\left(\mathrm{CD}_{3} \mathrm{OD}, 500 \mathrm{MHz}\right) \delta: 3.72$ $(1 \mathrm{H}, \mathrm{br} \mathrm{s}, \mathrm{H}-3), 2.13(1 \mathrm{H}, \mathrm{d}, J=5.5 \mathrm{~Hz}, \mathrm{H}-18), 1.11(3 \mathrm{H}$, s, H-25), 1.06 (9H, s, H-24, 26, 27), $0.94(3 \mathrm{H}, \mathrm{d}, J=5 \mathrm{~Hz}$, $\mathrm{H}-29), 0.86(3 \mathrm{H}, \mathrm{d}, J=2 \mathrm{~Hz}, \mathrm{H}-30) .{ }^{13} \mathrm{C}-\mathrm{NMR}\left(\mathrm{CD}_{3} \mathrm{OD}\right.$, $125 \mathrm{MHz})$ 8: 179.7 (C-28), 138.5 (C-13), 125.3 (C-12), 73.2 (C-3), 65.6 (C-24), 64.5 (C-2), 53.1 (C-18), 44.1 (C-4), 41.4 (C-14), 41.3 (C-1), 39.5 (C-19), 39.1 (C-20), 39.1 (C-10), 39.1 (C-8), 37.8 (C-22), 33.2 (C-7), 29.4 (C21), 27.8 (C-15), 24.0 (C-16), 23.2 (C-11), 22.8 (C-23), 21.9 (C-27), 20.3 (C-30), 17.9 (C-29), 17.9 (C-6), 16.4 (C26), 16.4 (C-25). The above data were identical to the literature data [49].

Kaempferol-3-O- $\alpha$-L-rhamnopyranoside-7-O- $\alpha$-L-rhamopyranoside (23). Yellow powder, $\mathrm{mp} 200-202^{\circ} \mathrm{C}$. IR $\left(\mathrm{KBr}, \mathrm{cm}^{-1}\right) v_{\max }: 3420,2911,1651,1605,1022 .{ }^{1} \mathrm{H}-$ NMR (CD $\left.{ }_{3} \mathrm{OD}, 500 \mathrm{MHz}\right) \delta: 7.78\left(2 \mathrm{H}, \mathrm{d}, J=7 \mathrm{~Hz}, \mathrm{H}-2^{\prime}\right.$, $\left.-6^{\prime}\right), 6.92\left(2 \mathrm{H}, \mathrm{d}, J=5.5 \mathrm{~Hz}, \mathrm{H}-3^{\prime},-5^{\prime}\right), 6.71(1 \mathrm{H}, \mathrm{d}, J=$ $1.5 \mathrm{~Hz}, \mathrm{H}-8), 6.44(1 \mathrm{H}, \mathrm{d}, J=1.5 \mathrm{~Hz}, \mathrm{H}-6), 5.54(1 \mathrm{H}, \mathrm{br}$ s, H-1"), $5.38\left(1 \mathrm{H}, \mathrm{s}, 22^{\prime \prime}-\mathrm{OH}\right), 4.57(1 \mathrm{H}$, br s, H-2"), $4.00\left(1 \mathrm{H}\right.$, br s, H-2"'), $3.80\left(1 \mathrm{H}, \mathrm{m}, \mathrm{H}-3^{\prime \prime}\right), 3.59(1 \mathrm{H}, \mathrm{m}$, H-3"'). ${ }^{13} \mathrm{C}-\mathrm{NMR}\left(\mathrm{CD}_{3} \mathrm{OD}, 125 \mathrm{MHz}\right) \delta: 178.4$ (C-4), 162.2 (C-7), 161.6 (C-5), $160.4\left(\mathrm{C}-4^{\prime}\right), 158.4(\mathrm{C}-2), 156.7$

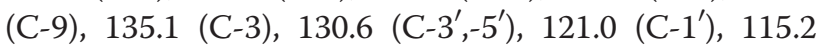
(C-2', -6'), 106.2 (C-10), $102.1\left(\mathrm{C}-1^{\prime \prime}\right), 99.2(\mathrm{C}-6), 98.5$ (C-1"'), 94.2 (C-8), 72.3 (C-2"), 71.8 (C-4"'), 70.8 (C4"'), 70.7 (C-3"'), 70.7 (C-5"'), 70.5 (C-3"), 70.3 (C-2"'), 69.9 (C-5"), 16.7 (C-6"'), 16.4 (C-6"). The above data were identical to the literature data [50].

\section{Cell lines and culture}

MGC-803, PC3, A375, and NIH3T3 cell lines were obtained from the Institute of Biochemistry and Cell Biology, China Academy of Science. MGC-803 is stomach cancer cell line, PC3 is prostate cancer cell line, A375 is malignant melanoma cell line, and NIH3T3 is mouse fibroblast cell line. The entire cancer cell lines were maintained in the RPMI 1640 medium and NIH3T3 was maintained in the DMEM medium. They were supplemented with $10 \%$ heat-inactivated fetal bovine serum (FBS) in a humidified atmosphere of $5 \% \mathrm{CO}_{2}$ at $37^{\circ} \mathrm{C}$. All cell lines were maintained at $37^{\circ} \mathrm{C}$ in a humidified $5 \%$ carbon dioxide and $95 \%$ air incubator.

\section{MTT assay}

All tested extracts and compounds were dissolved in DMSO and subsequently diluted in the culture medium before treatment of the cultured cells. When the cells were $80-90 \%$ confluent, they were harvested by treatment with a solution containing $0.25 \%$ trypsin, thoroughly washed and resuspended in supplemented growth medium. Cells $\left(2 \times 10^{3} /\right.$ well $)$ were plated in $100 \mu \mathrm{L}$ of medium/well in 96well plate. After incubations overnight, the cells were treated with different concentrations of extracts in RPMI 1640 with $10 \%$ FBS for $72 \mathrm{~h}$. In parallel, the cells treated with $0.1 \%$ DMSO served as negative control and ADM (Adriamycin) as positive control. Finally, $100 \mu \mathrm{L}$ of MTT (Beyotime Co., Jiangsu, China) was added, and the cells were incubated for $4 \mathrm{~h}$. The MTT-formazan formed by metabolically viable cells was dissolved in $100 \mu \mathrm{L}$ of SDS for $12 \mathrm{~h}$. The absorbance was then measured at $595 \mathrm{~nm}$ with a microplate reader (BIO-RAD, model 680), which is directly proportional to the number of living cells in culture [51].

\section{AO/EB staining}

The cells were seeded at a concentration of $5 \times 10^{4}$ cell/ $\mathrm{mL}$ in a volume of $0.6 \mathrm{~mL}$ on a sterile cover slip in 6well tissue culture plates. Following incubation, the medium was removed and replaced with fresh medium plus $10 \%$ FBS and then supplemented with compounds. After the treatment period, the cover slip with monolayer cells was inverted on the glass slide with $20 \mu \mathrm{L}$ of AO/EB (Beyotime Co., Shanghai, China) stain (100 $\mu \mathrm{g} /$ $\mathrm{mL})$. The fluorescence was read using an IX71SIF-3 fluorescence microscope (OLYMPUS Co., Toukyu Met, Japan).

\section{Hoechst 33258 staining}

The cells grown on the sterile cover slip in 6-well tissue culture plates were treated with compounds for a certain range of treatment time. The culture medium containing compounds was removed, and the cells were fixed in $4 \%$ paraformaldehyde for $10 \mathrm{~min}$. The cells were washed twice with $\mathrm{PBS}$, and were consequently stained with $0.5 \mathrm{~mL}$ of Hoechst 33258 staining (Beyotime Co., Jiangsu, China) for $5 \mathrm{~min}$. The stained nuclei were washed twice with PBS, and were consequently observed 
under an IX71SIF-3 fluorescence microscope at $350 \mathrm{~nm}$ excitation and $460 \mathrm{~nm}$ emissions.

\section{TUNEL assay}

TUNEL assays were performed using a colorimetric TUNEL apoptosis assay kit according to the manufacturer's instructions (Beyotime). The cells grown in 6-well culture clusters were treated as mentioned in mitochondrial depolarization assay. The MGC-803 cells grown in 6-well tissue culture plates were washed with PBS and fixed in $4 \%$ paraformaldehyde for $40 \mathrm{~min}$. The cells were washed once with PBS, and were consequently permeabilized with immunol staining wash buffer (Beyotime) for $2 \mathrm{~min}$ on ice. The cells were rewashed once with PBS, and were consequently incubated in $0.3 \% \mathrm{H}_{2} \mathrm{O}_{2}$ in methanol at room temperature for $20 \mathrm{~min}$ to inactivate the endogenous peroxidases, after which the cells were washed thrice with PBS. Thereafter, the cells were incubated with $2 \mu \mathrm{L}$ of TdT-enzyme and $48 \mu \mathrm{L}$ of BiotindUTP per specimen for $60 \mathrm{~min}$ at $37^{\circ} \mathrm{C}$. The cells were terminated for $10 \mathrm{~min}$, and were consequently incubated with streptavidin-HRP (50 $\mu \mathrm{L}$ per specimen) conjugate diluted at 1:50 in sample diluent for $30 \mathrm{~min}$. The cells were washed three times with PBS, and were consequently incubated with diaminobenzidine solution (200 $\mu \mathrm{L}$ per specimen) for $10 \mathrm{~min}$. Thereafter, the cells were rewashed twice with PBS, and were consequently imaged under an XDS-1B inverted biological microscope (Chongqing Photoelectric Devices Co. Chongqing, China).

\section{Flow cytometry analysis}

Prepared MGC-803 cells $\left(1 \times 10^{6} / \mathrm{mL}\right)$ were washed twice with cold PBS and then re-suspended gently in $500 \mu \mathrm{L}$ binding buffer. Thereafter, cells were stained in 5 $\mu \mathrm{L}$ Annexin V-FITC and shaked well. Finally, $5 \mu \mathrm{L}$ PI was added to these cells and incubated for $20 \mathrm{~min}$ in a dark place, analyzed by FACS Calibur, Becton Dickinson.

\section{Statistical analysis}

All statistical analyses were performed using SPSS 10.0, and the data were analyzed using one-way ANOVA. The mean separations were performed using the least significant difference method. Each experiment was performed in triplicate, and all experiments were run thrice and yielded similar results. Measurements from all the replicates were combined, and the treatment effects were analyzed.

\section{Competing interests}

All the authors declare that they have no competing interests.

\section{Authors' contributions}

Shengjie Yang and Mingchuan Liu performed the experiments, analyzed the data and wrote the paper. Na Liang and Qi Zhao performed the experiments. Yuping Zhang and Wei Xue planned and analyzed the data, and Song Yang planned the experiments, wrote the paper and give final approval of the version to be published. All authors contributed to this study, read and approved the final manuscript.

\section{Acknowledgements}

The authors wish to thank the National Key Program for Basic Research (Nos.2010CB126105, 2010CB134504), the National Natural Science Foundation of China (Nos. 21132003, 21172048), Guizhou Province S\&T Program (No. 20103052) for the financial support.

Received: 16 December 2012 Accepted: 16 January 2013 Published: 4 February 2013

\section{References}

1. Jiangsu New Medical College: Dictionary of Chinese Materia Medica.; 2001

2. Socolsky C, Arena ME, Asakawa Y, Bardon A: Antibacterial prenylated acylphloroglucinols from the fern Elaphoglossum yungense. J Nat Prod 2010, 73:1751-1755.

3. Kapadia GJ, Tokuda H, Konoshinma T: Anti-tumor promoting activity of Dryopteris Phlorophenone derivatives. Cancer let 1996, 105:161-165.

4. Zhao ZL, Leng CH, Wang ZT: Identification of Dryiopteris crassirhizoma and the adulterant species based on $\mathrm{CPDNA}$ rbcL and translated amino acid sequences. Planta Med 2007, 73:1230-1233.

5. Ito H, Muranaka T: Ichthyotoxic pholroglucinol derivatives from Dryopteris fragrans and their antitumor promoting acitivity. Chem Pharm Bull 2000, 48:1190-1192.

6. Attari F, Sepehri H, Delphi L, Goliaei B: Apoptotic and necrotic effects of pectic acid on rat pituitary GH3/B6 tumor cells. Iran Bio J 2009, 13:229-236.

7. Shao JW, Dai YC, Xue JP, Wang JC, Lin FP, Guo YH: In vitro and in vivo anticancer activity evaluation of ursolic acid derivatives. Eur J Med Chem 2011, 46:2652-2661.

8. Chiganças V, Miyaji EN, Muotri AR, de Fátima Jacysyn J, Amarante-Mendes GP, Yasui A, Menck CF: Photorepair prevents ultraviolet-induced apoptosis in human cells expressing the marsupial photolyase gene. Cancer Res 2000, 60:2458-2463.

9. Bhattacharyya SS, Mandal SK, Biswas R, Paul S, Pathak S, Boujedaini N, Belon P, Khuda-Bukhsh AR: In vitro studies demonstrate anticancer activity of an alkaloid of the plant Gelsemium sempervirens. Exp Biol Med 2008, 233:1591-1601.

10. Yuan K, Song B, Jin L, Xu S, Xu X, Yang S: Synthesis and biological evaluation of novel 1-aryl, 5(phenoxy-substituted)aryl-1,4-pentadien-3one derivatives. Med Chem Commn 2011, 2:585-589.

11. Kasibhatla S, Amarante-Mendes GP, Finucane D, Brunner T, Bossy-Wetzel E, Green DR: Staining of suspension cells with hoechst 33258 to detect apoptosis. SH Protoc 2006, 4:123-130.

12. Ribble D, Goldstein NB, Norris DA, Shellman YG: A simple technique for quantifying apoptosis in 96-well plates. BMC Biotechnol 2005, 5:1-12.

13. Ariffin $\mathrm{SHZ}, \mathrm{Omar} W H H$, Ariffin $\mathrm{ZZ}$, Safian MF: Intrinsic anticarcinogenic effects of Piper sarmentosum ethanolic extract on a human hepatoma cell line. Cancer Cell Int 2009, 9:1-6.

14. Meng C, Wu S, Xing D: Real-time fluorescence imaging of sirt1 cytosolic translocation under the treatment of growth factor deprivation. J Innov Opt Heal Sci 2011, 2:133-141.

15. Wu YL, Sun B, Zhang XJ, Wang SN, He HY, Qiao MM, Zhong J, Xu JY: Growth inhibition and apoptosis induction of Sulindac on human gastric cancer cells. World J Gastroenterol 2001, 7:796-800.

16. Zhang M, Zhang H, Sun C: Targeted constitutive activation of signal transducer and activator of transcription 3 in human hepatocellular carcinoma cells by cucurbitacin B. Cancer Chemoth Pharmacol 2009, 63:635-642.

17. Hashemi M, Karami-Tehrani F, Ghavami S, Maddika S, Los M: Adenosine and deoxyadenosine induces apoptosis in oestrogen receptor-positive and -negative human breast cancer cells via the intrinsic pathway. Cell Prolif 2005, 38:269-285.

18. Juan ME, Wenzel U, Ruiz-Gutierrez V, Daniel H, Planas JM: Olive fruit extracts inhibit proliferation and induce apoptosis in HT-29 human colon cancer cells. J Nutr 2006, 136:2553-2557.

19. Qing H, Xu H, Wei Z, Gibson K, Li XM: The ability of atypical antipsychotic drugs vs. haloperidol to protect PC12 cells against MPP +-induced apoptosis. Eur J Neurosci 2003, 17:1563-1570. 
20. Li WB, Feng J, Geng SM, Zhang PY, Yang XN, Hu G: Induction of apoptosis by Hax-1 siRNA in melanoma cells. Cell Biol Int 2009, 4:548-554.

21. Yuan Y, Bian JC, Liu XZ, Zhang Y, Sun Y, Liu ZP: Oxidative stress and apoptotic changes of rat cerebral cortical neurons exposed to Cadmium in vitro. Biomed Environ Sci 2012, 25:172-181.

22. Oberhammer F, Fritsch G, Schmied M, Pavelka M, Printz D, Purchio T, Lassmann H, Schulte-Hermann R: Condensation of the chromatin at the membrane of an apoptotic nucleus is not associated with activation of an endonuclease. J Cell Sci 1993, 104:317-326.

23. Popper P, Farber DB, Micevych PE, Minoofar K, Bronstein JM: TRPM-2 expression and tunel staining in neurodegenerative diseases: studies in wobbler and rd mice. Exp Neurol 1997, 143:246-254.

24. Kundrotiene J, Wagner A, Liljequist S: Fluoro-Jade and TUNEL staining as useful tools to identify ischemic brain damagefollowing moderate extradural compression of sensorimotor cortex. Acta Neurobiol Exp 2004, 64:153-162.

25. Nishizaki K, Yoshino T, Orita Y, Nomiya S, Masuda Y: TUNEL staining of inner ear structures may reflect autolysis, not apoptosis. Hear Res 1999, 130:131-136.

26. Sakic B, Maric I, Koeberle PD, Millward JM, Szechtman H, Maric D, Denburg JA: Increased TUNEL staining in brains of autoimmune Fas-deficient mice. J Neuroimmunol 2000, 104:147-154.

27. Orita Y, Nishizaki K, Sasaki J, Kanda S, Kimura N, Nomiya S, Yuen K, Masuda $Y$ : Does TUNEL staining during peri- and post-natal development of the mouse inner ear indicate apoptosis? Acta Otolaryngol Supp/ 1999. 540:22-26.

28. Herzenberg LA, Tung J, Moore WA, Herzenberg LA: Interpreting flow cytometry data: a guide for the perplexed. Nat Immunol 2006, 7:681-685.

29. Stemberger J, Witt V, Printz D, Geyeregger R, Fritsch G: Novel singleplatform multiparameter FCM analysis of apoptosis: Significant differences between wash and no-wash procedure. Cytom A 2010, 77:1075-1081

30. Xu X, Liu J, Deng X: FCM, SSR and CAPS analysis of intergeneric somatic hybrid plants between Changshou kumquat and Dancy tangerine. Bot Bull Acad Sin 2005, 46:93-98.

31. Fujita M, Inoue T, Nagai M: O-methylation effect on the carbon-13 nuclear magnetic resonance signals of ortho-substituted Phenols II. Yakugaku Zasshi 1985, 105:240-243.

32. Murakami T, Chen CC: Uber die bestandteile der rhizome von Woodwardia orientalis Sw. Chem Pharm Bull 1971, 19:25-30.

33. De Oliveira PES, Conserva LM, De Simone CA: A pimpinellin monomer and dimer isolated from the roots of Esenbeckia grandiflora. Acta Cryst 2004, C60:0900-0902

34. Stenhagen E, Abrahamsson S, Fred WM: Registry of Mass Spectral Data. New York, US: John wiley and Sons Inc; 1974.

35. Sliva MGV, Vieira IGP, Mendes FNP, Albuquerque IL, Santos RND: Variation of ursolic acid content in eight ocimum species from northeastern Brazil. Molecules 2008, 13:2482-2487.

36. Joshi KC, Bansal RK, Singh P: Mass \& NMR spectral studies of sitost-4-en-3one from Tabebuia rosea DG. Indian J Chem 1974, 12:903.

37. Winston FT, Lynn CB, Azzam A: Lupanetriterpenoids of Salacia Cordata. J Nat Prod 1992, 3:395-398.

38. Itokawa H, Suto K, Takeya K: Studies on a novel P-coumaroyl glucoside of apigenin and on other flavonoids isolated from Patchouli. Chem Pharm Bull 1981, 29:254-256.

39. Murakami T, Chen CM: Uber die bestandteile der rhizome von Woodwardia orientalis Sw. Chem Pharm Bull 1971, 19:25.

40. Mizuno M, linuma M, Tanaka T: Sutchuenoside A: A New kempferol glycoside from the aerial parts of Epimedium Sutchuenense. J Nat Prod 1991, 54:1427-1429.

41. Toker G, Memisoglu M, Yesilada E, Aslan M: Main flavonoid of Tilia argentea DESF. ex DC. leaves. Turk J Chem 2004, 28:745-749.

42. Gen IN: A new class of dimeric flavan-3-ol gallates, theasinensins A and $B$, and proanthocyanidin gallates from green tea leaf. Chem Pharm Bull 1983, 31:3906-3914.

43. Tanaka T, Nonaka G, Nishioka I: 7-O-galloyl-(+)-catechin and 3-O-galloyl procyanidin B-3 from Sanguisorba officinalis. Phytochemistry 1983, 22:2575-2578

44. Hu XL, Zhu H, Liu CR, Tu PF: Study on the chemical constituents of the flowers of Impatiens balsamina L. Chin Tradit Patent Med 2003, 25:833-834.
45. Li LM, Pu JX, Xiao WL, Sun HD: Triterpenes from Isodon xerophilus. Chin J Nat Med 2002, 10:307-310.

46. Fang SY, He AS, Gao JF: Triterpenoids from Adina rubella. J Nat Prod 1996, 59:304-307.

47. Byung SM, Miyuki T, MA CM, Norio N, Masao H: Kaempferol acetylrhamnosides from the rhizome of Dryopteris crassirhizoma and their inhibitory effects on three different activities of human immunodeficiency virus-1 reverse transcriptase. Chem Pharm Bull 2001, 49:546-550

48. Masuda T, Jitoe A, Kato S: Acetylated flavonol glycosides from Zingiber zerumbet. Phytochemistry 1991, 30:2391-2394.

49. Jinsaku S, Toyo K, Haruyo F, Toyokazu O: $6 \beta$-hydroxyursolic acid and other triterpenoids of Enkianthus cernuus. Phytochemistry 1983, 22:2553-2555.

50. Luan $X$, Wang $H$, Wen YY: Studies on the chemical constituents of Woodwardia japonica. J Trop Subtrop Botany 2002, 10:361-365.

51. Dehelean CA, Şoica C, Ledeți I, Aluaş M, Zupko I, Găluşcan A, Cinta-Pinzaru S, Munteanu M: Study of the betulin enriched birch bark extracts effects on human carcinoma cells and ear inflammation. Chem Cent J 2012, 6:137.

doi:10.1186/1752-153X-7-24

Cite this article as: Yang et al:: Discovery and antitumor activities of constituents from Cyrtomium fortumei (J.) Smith rhizomes. Chemistry Central Journal 2013 7:24.

Publish with ChemistryCentral and every
scientist can read your work free of charge
"Open access provides opportunities to our
colleagues in other parts of the globe, by allowing
anyone to view the content free of charge."
W. Jeffery Hurst, The Hershey Company.
- available free of charge to the entire scientific community
- peer reviewed and published immediately upon acceptance
- cited in PubMed and archived on PubMed Central
- yours - you keep the copyright
submit your manuscript here:
htt://www.chemistrycentral.com/manuscript/

